The BDJ News section accepts items that include general news, latest research and diary events that interest our readers. Press releases or articles may be edited, and should include a colour photograph if possible. Please direct your correspondence to the News Editor, Arveen Bajaj at the BDJ, The Macmillan Building, 4 Crinan Street, London N19XW or by email to bdj@bda.org

\section{First meeting of implementation group}

The Government's implementation group to assess the impact of the NHS dentistry reforms held its first meeting on 24 April. Participants included representatives from Citizens Advice, the British Dental Health Foundation, the British Orthodontic Society, the Welsh Assembly Government, the Dental Laboratories Association, strategic health authorities, primary care trusts and the NHS Business Services Authority.

The Department of Health said the group would monitor closely the evidence of how the new system was working in practice and look at whether changes would be needed. The BDA was offered a place on the group for a General Dental Practice Committee (GDPC) representative and also for a staff member.

Linda Wallace, Director of Professional Services at the BDA, attended this first meeting. Future involvement with the implementation group will be discussed at the next meeting of the GDPC.

\section{CDA 5th Triennial General and Scientific Meeting}

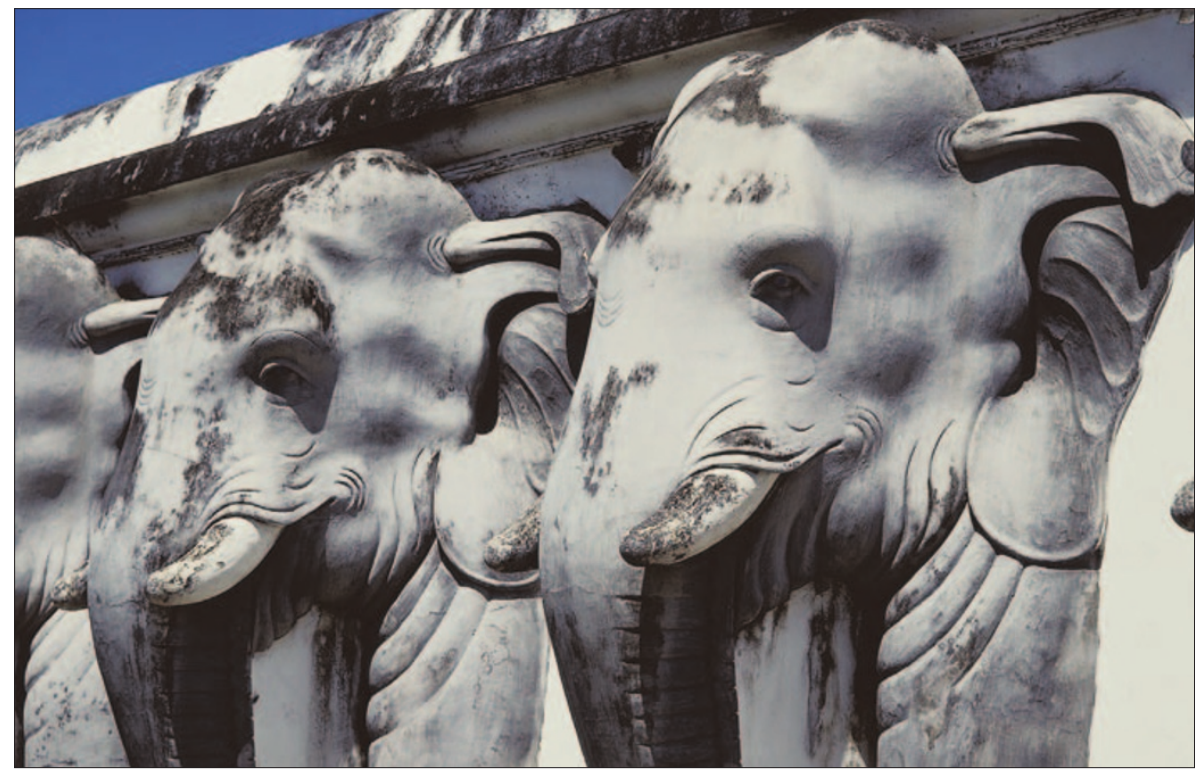

The Commonwealth Dental Association (CDA) will be holding its 5th Triennial General and Scientific Meeting in Colombo, Sri Lanka from 1-3 December 2006. The conference is being organised by the Sri Lankan Dental Association and the scientific programme will carry the title 'Yesterday, Today, Tomorrow', with speakers on subjects including aesthetic dentistry, endo- and orthodontics and oral medicine.

As well as the scientific programme, a parallel political workshop entitled 'The oral health workforce in the Commonwealth - priority issues' will take place during the second day of the meeting. There will also be full dental trade and oral health exhibitions and a full social programme. In addition, pre- and post-conference tours are being arranged, which will include visits to Kandy, Sigiraya, Rock Fortress, Pinnawala and the elephant orphanage. For more information contact Mrs Julia Campion on 02072293931 or email JuliaCampion@cdauk.com.

\title{
Standing is best
}

New research shows that sitting in a slumped position for prolonged periods significantly reduces lung capacity, expiratory flow and lumbar lordosis (the natural curvature of the spine).

With modern surgery and laboratory design, the majority of dental team members are seated for much of their working lives. Good posture while seated is readily recognised as essential for good back health but the recently reported research suggests that it may also be of more significance than previously thought in lung and breathing function. The study, from the Rehabilitation Institute in Chicago, assessed four different postures; normal, with full ischial support and flat lumbar support; slumped, with pelvis positioned against the backrest; against the back part of the seat without ischial support, with partially removed ischial support and an enhanced lumbar support and standing.

Standing provided the best lung capacity, expiratory flow and lumbar lordosis with the slumped seating posture causing significantly decreased values on all measures.

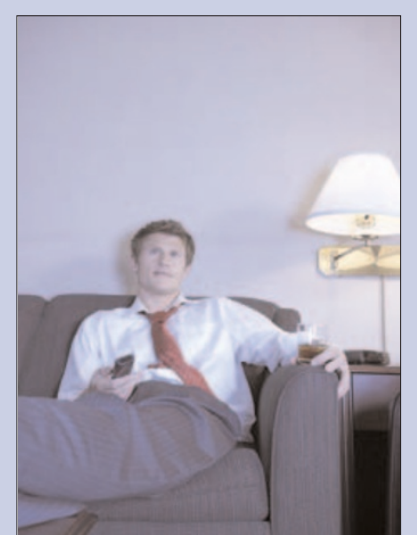




\section{DIARY}

May

8th Oxford Course in Evidence Based

Dentistry

Venue: Rewley House, Department for Continuing Education, Oxford University

Date: 15-19 May 2006

Tel: 01865286941

Email: cpdhealth@conted.ox.ac.uk

www.conted.ox.ac.uk/health

2006 British Dental Conference and

Exhibition

'Making it work together'

Venue: International Conference Centre, Birmingham

Date: 18-20 May 2006

Tel: 08701666625

www.bda-events.org

June

10th European Congress Dentomaxillofacial Radiology

Venue: Provinciehuis, Leuven, Belgium

Date: 31 May - 2 June 2006

www.10ecdmfr.be

112th Meeting of the American Dental

Society of Europe

Venue: Dubrovnik, Croatia

Date: 27-30 June 2006

Tel: 01413310088

www.adse.co.uk

July

82nd Congress of the European Orthodontic Society

Venue: Hofburg Congress Center, Vienna, Austria

Date: 4-8 July 2006

Tel: $(+43 / 1) 53116-38$

Fax: (+43/1) $53116-61$

Email: azmedinfo@media.co.at

September

The British Society of Paediatric Dentistry Annual Scientific Conference

'The Art \& The Science'

Venue: The Hilton, Leeds City

Date: 12-15 September 2006

www.bspd.co.uk/conf-2006.html

FDI Annual World Dental Congress Venue: Shenzhen, China

Date: 22-25 September 2006

Email: congress@fdiworldental.org www.fdiworldental.org

\section{Key Skills wins prestigious award}

The Faculty of General Dental Practice (UK)'s e-learning package, Key Skills in Primary Dental Care, has received a silver award at the 40th anniversary International Visual Communication Association (IVCA) awards.

Entries are judged by over 200 jury members looking for programmes that clearly communicate the client's aims and objectives and interpret their subject matter in an original, creative and appropriate manner.

Bronze, silver and gold awards were made in 28 categories and the FGDP(UK) and its development partner Smile-on Ltd were delighted with their silver in the 'Interactive Multimedia Publishing' category. Mike Mulcahy, Dean of the FGDP(UK), said 'This prestigious award is just recognition for Key Skills, which is now acknowledged by many authorities as a leading, innovative educational tool for clinical effectiveness.'

The IVCA awards are Europe's leading business communication awards and are internationally acknowledged as benchmarks for effective communication. Mr Mulcahy said that Smile-on Ltd and the FGDP(UK) were particularly elated to be in such company as the overall winner on the night, the final presentation in London's bid for the 2012 Olympics.

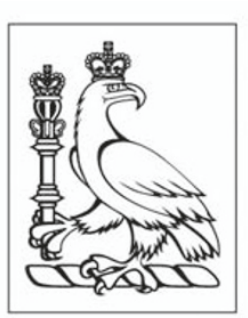

Faculty of General Dental Practice (UK) The Royal College of Surgeons of England

\section{Dentaid launches Bright Bites}

The oral health charity Dentaid have launched a major new education initiative. Developed with funding from the Department of Health, Bright Bites is a comprehensive learning tool designed for dental professionals and schools to teach UK children the importance of good oral hygiene and a balanced diet. The project was officially launched by health minister Rosie Winterton on 24 March at St Peter's Catholic Primary School, Doncaster.

The programme is based around an interactive CD-ROM featuring 'Charlie', the Bright Bites hero. Children explore his house visiting different rooms, each teaching them about a different aspect of oral health and diet using games and video clips.

The CD-ROM forms part of a teaching pack that has been distributed to all state primary schools in England to help meet the objectives of the Key Stage 2 curriculum.

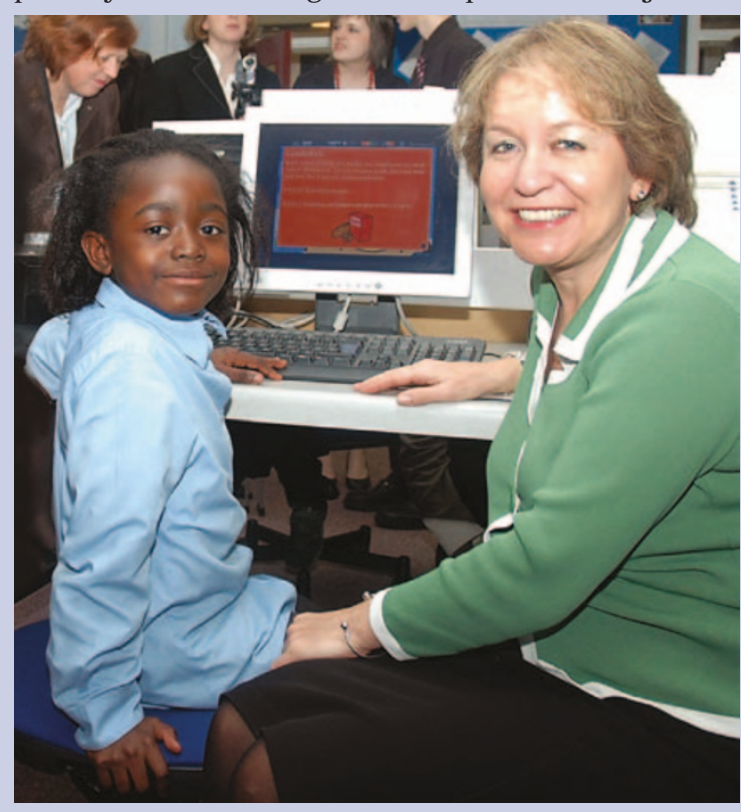
The pack has also been designed with dental professionals in mind and is just as appropriate for oral health education within the practice environment. A CD-only version is available to run in the waiting room and retail packs can be sold by practices either on a profit making basis, or as a not-for-profit option to support Dentaid's charity work around the world.

Rosie Winterton, pictured at the launch, said 'Bright Bites promises to have a real impact on the oral health education of England's children.' Further information on the project can be found at www.brightbites.org. 


\section{No risk from amalgam fillings}

Two new studies have concluded that amalgam fillings do not lead to neurological or renal disorders in children. The papers, both published in the Journal of the American Medical Association, provide more evidence that amalgam restorations are safe to use and pose no risk to human health.

In the first study (Bellinger D C, Trachtenberg F, Barregard L et al. J Am Med Assoc 2006; 295: 1775-1783), researchers monitored a group of 534 six- to 10 -year-olds in New England for five years after they had been randomly assigned either amalgam fillings or fillings containing no mercury. They looked at the children's IQ, memory, cognitive function and kidneys to see if they were affected by the fillings. The second study looked at a group of 507 children with amalgam fillings in Lisbon, Portugal (DeRouen T A, Martin M D, Leroux B G et al. J Am Med Assoc 2006; 295: 1784-1792) and monitored them for seven years to see whether the fillings had any neurological effects.

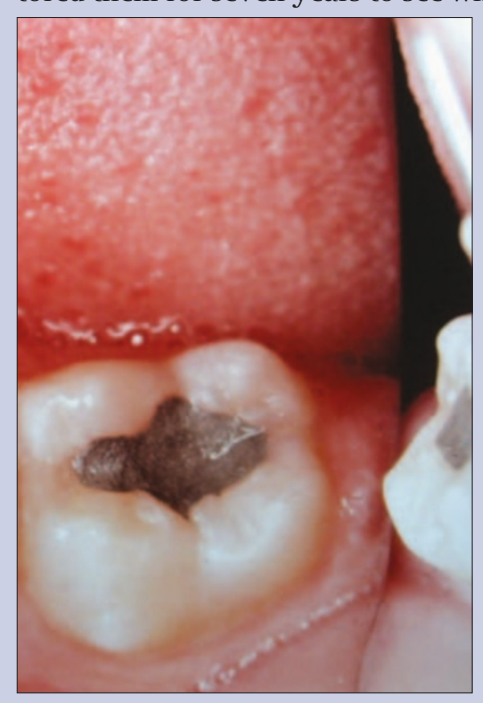

Although children with amalgam fillings were found to have slightly higher levels of mercury in their urine than control groups, both studies found no significant differences between children with amalgam fillings and those with resin composite fillings containing no mercury. The authors of the first study conclude that 'Under the conditions of use represented in this trial, there is no reason to discontinue use of mercury amalgam as the standard of care for caries in posterior teeth.'

It is hoped that these new results will help to reassure those concerned about the safety of amalgam as a dental restorative. Despite previous studies showing similar results to the recent findings, fears that amalgam fillings are not completely safe have persisted since the 1980s, when scientists showed that amalgam fillings released mercury vapour into the mouth that was then inhaled and absorbed by the body.

\section{Primary Care Support Service for Wales launched}

A new service providing counselling, support and education to GPs, dentists and community pharmacists across the NHS has been launched in Bangor, North Wales. The Primary Care Support Service is an independent, direct access service led from the University of Wales, Bangor, with co-ordinators in each of the three Welsh regions.

The service will be supported by 100 professionals across Wales and has received funding from the Welsh Assembly Government. Dr Sue Ellison, who is leading the service, said: 'By being in the front line, GPs, dentists and pharmacists are often the first people to take on the consequences of change in the NHS. In the face of continuous external change, there are personal changes they can make that would enhance their quality of life.'

GPs, dentists and community pharmacists will have direct access to fully qualified counsellors, psychotherapists and clinical psychologists by telephone, with contact details being provided in three regional information guides that have been sent out to all primary healthcare professionals. The support element of the service will allow practitioners to contact colleagues by telephone in confidence for peer support, and will also have a service providing support for those under investigation of a complaint. In addition, the educational service will offer a range of sessions and courses that will focus on learning additional skills to help manage the many stresses practitioners are exposed to in a more positive way. This will be integrated with practitioners' own CPD programmes wherever possible.

'Our purpose is to provide a service which supports practitioners' development and which helps them manage their many pressures' continued Dr Ellison. 'We can all keep learning and positively growing.' 


\section{Eastman launches special care dentistry qualifications}

The UCL Eastman Dental Institute has announced two new postgraduate qualifications in special care dentistry. Building on its already successful postgraduate programmes, the Institute has established part-time taught courses leading towards a Certificate or Diploma in special care dentistry. Both programmes will deliver teaching and clinical experience in all aspects of this specialist area, and will provide the opportunity for participants to be taught by national and international leaders in the field.

The Certificate programme will comprise two part-time modules, while three part-time modules will make up the Diploma course. More information on the new programmes can be obtained from Karen Rhatigan on 020 79051244 or by email at k.rhatigan@eastman.ucl.ac.uk.

\section{UCL Qastman instirut:}

\section{BDHF elects new President}

The British Dental Health Foundation (BDHF) elected Dennis Carroll as its new President during its AGM in March. Dennis takes over the role from Stuart Boulton, who has reached the end of his two-year term.

Dennis is well known in the dental industry as a Past President of the British Dental Trade Association and long term General Manager of 3M Espe. He has been actively involved with the BDHF since 1990 and has been on the Trustee Board for the past eight years. Speaking at the handing over, Dennis said 'I am very proud and pleased to be elected as President of the British Dental Health Foundation. We are entering an interesting phase for dentistry in the UK and, with the Board's backing, I hope I will be able to make a real contribution to our future challenges and opportunities.'

Dennis' first act as President was to confirm Avril Joy's election as Honorary Vice President. He is pictured presenting his predecessor, Stuart Boulton, with the Past Presidents' Medal.

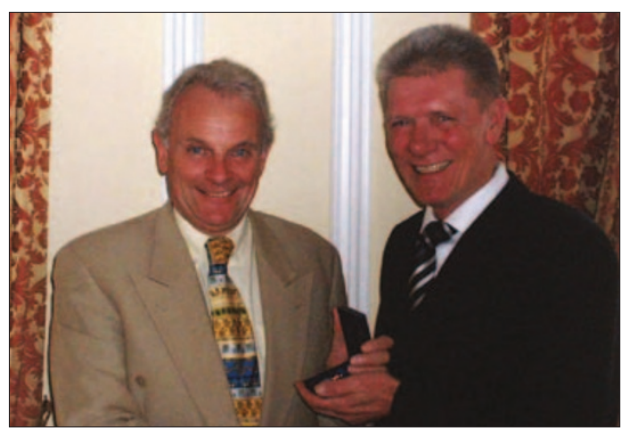

\section{Periodontal therapy may help diabetics}

A new study has provided support for the hypothesis that periodontal therapy may help diabetic patients improve their sugar control. The research, published in the April issue of the Journal of Periodontology, found an improvement in patients of up to 20\% at three and six months following treatment (Faria-Almeida R, Navarro A, Bascones A. J Periodontol 2006; 77: 591-598).

The study looked at patients' glycosylated haemoglobin, or HbA1c count. This measurement provides patients with a picture of their average blood sugar levels for the past two to three months, with a level between 4.0 and 6.0 indicating a healthy count. Conventional treatment for chronic moderate generalised periodontitis, including scaling and root planing, lowered the study group's HbA1c count from 7.2 to 5.7. 'This could significantly put diabetic patients who are just above the normal $\mathrm{HbA1c}$ range into the healthy range and reduce their risk of serious complications from diabetes,' say authors Antonio Bascones and Ricardo Faria-Almeida from the Complutense University in Madrid, Spain.

While Bascones cautions that the findings should not be considered definitive as the study does have limitations, the new evidence is being welcomed. 'For a long time we've known that diabetic patients have a higher risk of developing periodontal disease compared to non-diabetics,' said Kenneth A. Krebs, President of the American Academy of Periodontology. 'The results of this study provide additional evidence about the other side of the equation: that periodontal treatment may affect metabolic control in diabetic patients who have periodontal disease. While we can't say periodontal treatment will definitively help, to date no reports indicate a harmful effect of periodontal treatment on a diabetic patient's metabolic control.'

\section{Mrs Sue Hillman honoured on her retirement}

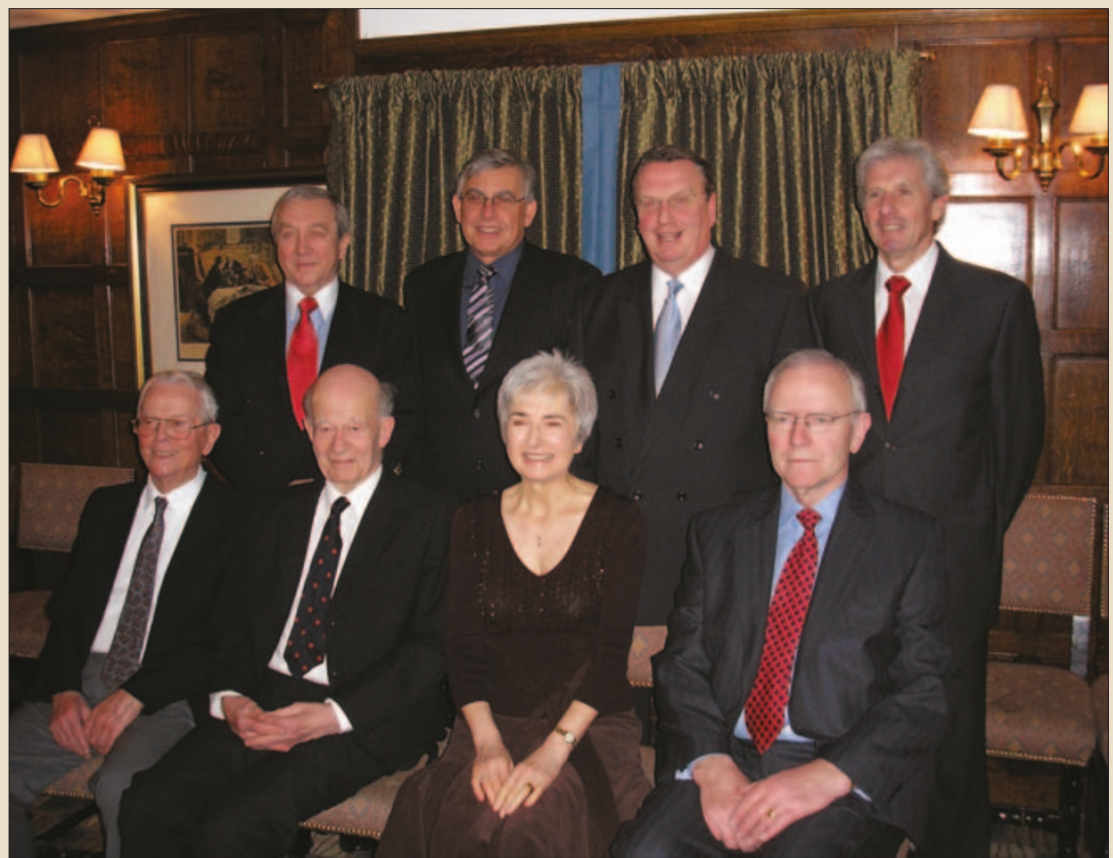

Seven former Deans of Manchester School of Dentistry recently gathered to attend a dinner in honour of the retirement of Mrs Sue Hillman. Employed at the School for 38 years, Mrs Hillman was originally appointed to the post of Assistant to the Dean by Professor J Moore. She has since worked with nine Deans, with her most recent role being Executive Assistant to the Head of School. She retired at the end of 2005. Pictured (left to right): back row - Professors F McCord, A S Blinkhorn, N Wilson and W Shaw; front row - Professors P Holloway and J R Moore, Mrs Sue Hillman and Professor J H Jones. 